\title{
EFFECT OF SITAGLIPTIN AND VILDAGLIPTIN ON WOUND HEALING IN MALE WISTAR RATS - AN EXPERIMENTAL STUDY
}

\author{
NETRAVATHI B ANGADI*, URMILA KAGAL, SOMALING TIMSHETTI
}

Department of Pharmacology, KLE academy of Higher Education and Research's (KAHER) J. N. Medical College, Nehru Nagar, Belagavi-590010, Karnataka, India. E-mail: drnetra.angadi@gmail.com

Received: 19 March 2018, Revised and Accepted: 08 May 2018

\section{ABSTRACT}

Objective: Diabetes mellitus (DM) is a spectrum of common metabolic disorders, arising from a variety of pathogenic mechanisms. With an increasing incidence worldwide, DM will be likely a leading cause of morbidity and mortality in the future. Delayed wound healing in diabetes is a major source of morbidity and mortality. Sitagliptin and Vildagliptin are novel antihyperglycemic agents used for the treatment of DM. The present study was planned to investigate the effect of Sitagliptin and Vildagliptin on various wound healing models in male Wistar rats.

Methods: Male Wistar rats (150-200 g) were divided into three groups, i.e., control, Sitagliptin, and Vildagliptin (n=6 animals in each group) for each wound model. Excision wound, resutured incision wound, and dead space wounds were inflicted under thiopentone anesthesia in male Wistar rats. The rats received Sitagliptin and Vildagliptin orally during the study period. Resutured incision was assessed by wound breaking strength; dead space wound was assessed by granuloma dry weight and histopathology of granulation tissue. In excision wounds, treatment was monitored by planimetry. Data were expressed as mean \pm standard error of mean and analyzed by analysis of variance followed by Dunnett's post hoc test. p $<0.05$ was considered statistically significant.

Results: Sitagliptin and Vildagliptin significantly promoted the healing process in all three wound models studied. Histopathological studies revealed increased collagen content and granulation tissue in Sitagliptin and Vildagliptin groups.

Conclusion: In all the three wound models studied, Sitagliptin and Vildagliptin promoted wound healing. The pro-healing effect of Sitagliptin and Vildagliptin needs to be explored clinically.

Keywords: Sitagliptin, Vildagliptin, Wound healing.

(c) 2018 The Authors. Published by Innovare Academic Sciences Pvt Ltd. This is an open access article under the CC BY license (http://creativecommons. org/licenses/by/4. 0/) DOI: http://dx.doi.org/10.22159/ajpcr.2018.v11i8.26061

\section{INTRODUCTION}

Diabetes mellitus (DM) is a spectrum of common metabolic disorders, arising from a variety of pathogenic mechanisms, all resulting in hyperglycemia [1]. DM is the leading cause of end-stage renal disease, non-traumatic lower extremity amputations, and adult blindness. It also predisposes to cardiovascular diseases. With an increasing incidence worldwide, DM will be likely a leading cause of morbidity and mortality in the future [2].

Davis Pryce recognized for the first time that "diabetes itself may play an active part in the causation of perforating ulcers" [3]. Yet despite more than a century of research, few pharmacologic approaches enhance the healing of diabetes-related wounds. Diabetes-related wounds continue to impose considerable clinical and economic burdens. The annual incidence of diabetic foot ulcers ranges from 1 to $4 \%$, suggesting that up to $25 \%$ of people with diabetes will develop foot ulcers sometime during their lives [4]. Moreover, 3- 5-year mortality rates in diabetic patients may reach $74 \%$ among those that undergo lower-extremity amputation. The prognosis for people with diabetic ulcers is worse than that associated [5].

Research has identified numerous changes in diabetic wounds that contribute to a delay in healing. Markedly abnormal patterns of growth factor and cytokine, chemokine, enzyme, or protease expression and activity are associated with impaired tissue repair [6]. Dysfunctional insulin signaling further compromises the disordered and disturbed wound healing. A study done in severely diabetic animals activated insulin receptors were virtually absent [6].

Targeting insulin release and resistance may, therefore, modulate impaired wound healing conditions. Glucagon-like peptide-1(GLP-1) receptor agonists and the dipeptidyl peptidase-4 (DPP-4) inhibitors are novel drugs in the treatment of DM. The effect of new treatments for diabetes on tissue regeneration may be of interest, although this aspect of antihyperglycemic pharmacology is relatively neglected. Very limited data characterize the effect of DPP-4 inhibitors on wound healing.

There is a paucity of information on the effect of Sitagliptin and Vildagliptin on wound healing. Hence, the present study was planned to investigate the effect of Sitagliptin and Vildagliptin on various wound healing models, namely resutured incision, excision, and dead space wounds.

\section{METHODS}

Healthy male adult Wistar rats weighing 150-200 g (procured from Central Animal House of the Institute) were housed individually and maintained on standard pellet diet with water ad libitum. The study protocol was approved by the institutional animal ethics committee. After careful depilation (under aseptic precaution) at the wounding site, the animals were starved overnight before the day of experimentation and divided into control and treatment group ( $\mathrm{n}=6$ in each) for each wound model. Sitagliptin $(9 \mathrm{mg} / \mathrm{kg}$ body weight of rat) [1] and Vildagliptin ( $9 \mathrm{mg} / \mathrm{kg}$ body weight of rat) [1] were administered orally in therapeutic equivalent doses as calculated with the help of conversion table devised by Paget and Barnes [7], while control group received equal volume of vehicle. The duration of treatment was 10 days for animals inflicted with incision and dead space wounds, while it was continued in animals bearing excision wounds till the complete closure of the wounds.

\section{Wound models [8-10]}

a. Resutured incision wounds: Under thiopentone anesthesia (dose of thiopentone i.p 20-40 mg), the animal was secured to operation 
table in its natural position. Two paravertebral straight incisions of $6 \mathrm{~cm}$ each were made through the entire thickness of the skin, on either side of the vertebral column with the help of a surgical blade. Wounds were closed with interrupted sutures $1 \mathrm{~cm}$ apart. Sutures were removed on the $8^{\text {th }}$ day, and breaking strength was measured on the $11^{\text {th }}$ day post-wounding by continuous water flow technique. Three readings were taken on each wound, and the mean of six such readings in each animal was used for statistical analysis. Subsequently, animals were sacrificed by overdose of anesthesia.

b. Excision wounds were made as described by Morton and Malone by excising the full thickness circular skin (approximately $500 \mathrm{~mm}^{2}$ ) from the nape of the neck under thiopentone anesthesia. Wound closure rate was assessed by planimetry on wounding day, followed by the $4^{\text {th }}, 8^{\text {th }}, 12^{\text {th }}, 16^{\text {th }}$, and $18^{\text {th }}$ day and subsequently on every alternate day till complete closure. Falling off the scab without any raw area indicated time for complete epithelialization and the same was noted. Similarly, scars were traced on complete epithelialization to assess wound contraction by noting scar size and shape. Wound healing was expressed as percentage closure of original wound area.

Percentage closure $=1-A_{d} / A_{0} \times 100$

where $A_{d}$ is the wound area on corresponding days and $A_{0}$ is the wound area on day 0 .

c. Dead space wounds were inflicted by implanting sterile cotton pellets measuring $10 \mathrm{mg}$ each and cylindrical grass piths $(25 \mathrm{~mm} \times 3 \mathrm{~mm})$ subcutaneously in the groin and axilla by the technique of D'Arcy et al. [11]. The granulation tissue was removed on the $11^{\text {th }}$ day post-wounding. All the granulation tissues were dissected out after sacrificing the animal and were dried at $60^{\circ} \mathrm{C}$ overnight to record the constant dry weight, expressed as $\mathrm{mg} / 100 \mathrm{~g}$ body weight [12]. One of the granulation tissues over the grass piths was opened and trimmed to a rectangular piece for the estimation of breaking strength. The other granulation tissues over the grass pith were preserved in $10 \%$ formalin for histopathological studies to evaluate the effect of Sitagliptin and Vildagliptin on collagen formation.

\section{Statistical Analysis}

The data for all the groups were expressed as mean \pm standard error of the mean and were analyzed by one-way analysis of variance followed by post hoc Dunnett's test using GraphPad Prism software and $\mathrm{p}<0.05$ was considered statistically significant.

\section{RESULTS}

Excision wounds: The rate of wound closure in Sitagliptin and Vildagliptin treated animals was significantly $(p<0.01)$ more on the $8^{\text {th }}, 12^{\text {th }}, 16^{\text {th }}$, and $18^{\text {th }}$ day as compared to that of control. The time for epithelialization was $23.40 \pm 0.81$ days in control group, while it was significantly $(\mathrm{p}<0.001)$ decreased in the Sitagliptin and Vildagliptin group with a mean value of $19.67 \pm 0.33$ and $19.83 \pm 0.40$ days, respectively (Table 1 and Graphs 1 and 2).

Resutured incision wounds: Sitagliptin and Vildagliptin significantly $(p<0.01)$ increased wound breaking strength compared to that of control (Table 2 and Graph 2).

Dead space wounds: Sitagliptin and Vildagliptin significantly $(p<0.05)$ increased breaking strength of granulation tissue similar to its effects in resutured incision wounds. Cotton pellet granuloma weight was increased significantly $(\mathrm{p}<0.01)$ in the Sitagliptin and Vildagliptin treated group $(47.74 \pm 2.29 \mathrm{mg} \%)$ as compared to that of control (32.28 $\pm 1.01 \mathrm{mg} \%$ ) (Table 2 and Graph 2). Histopathological studies revealed increased collagen content and granulation tissue in the Sitagliptin and Vildagliptin treated group in contrast to control group.

\section{DISCUSSION}

The number of individuals with diabetes is rising rapidly throughout the world. Both genetic and environmental factors contribute to its pathogenesis, which involves insufficient insulin secretion, reduced responsiveness to endogenous or exogenous insulin, increased glucose production, and/or abnormalities in fat and protein metabolism [1].

Delayed wound healing in diabetes is a major source of morbidity and mortality. It results from the combination of vasculopathy and neuropathy and often leads to minor and major amputations. Many



Graph 1: Effect of sitagliptin and vildagliptin on excision wound model parameters

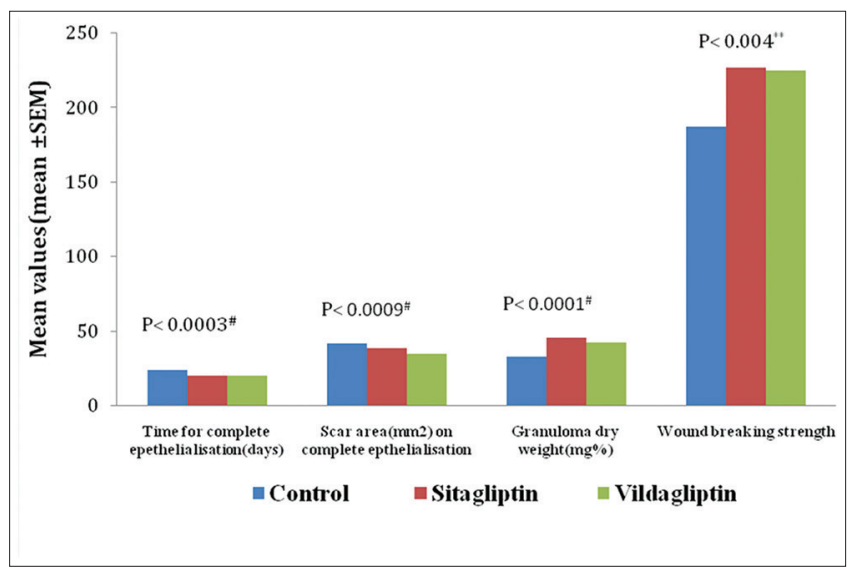

Graph 2: Compare of three groups on different parameters of wound healing wound model parameters

Table 1: Effect of Sitagliptin and Vildagliptin on excision wound model parameters. The values are represented as mean \pm SEM $(n=6)$

\begin{tabular}{|c|c|c|c|c|c|c|c|}
\hline \multirow[t]{2}{*}{ Group $(n=6)$} & \multicolumn{7}{|c|}{ Wound closure ( $\%$ of original area) in $\mathrm{mm}^{2}$ on day (Mean \pm SEM) } \\
\hline & $4^{\text {th }}$ day & $8^{\text {th }}$ day & $12^{\text {th }}$ day & $16^{\text {th }}$ day & $18^{\text {th }}$ day & Days for complete closure & Scar area $\left(\mathrm{mm}^{2}\right)$ \\
\hline Control & $18.52 \pm 2.85$ & $38.05 \pm 2.23$ & $59.37 \pm 3.41$ & $80.50 \pm 1.23$ & $90.81 \pm 0.64$ & $23.40 \pm 0.81$ & $41.60 \pm 0.67$ \\
\hline Sitagliptin & $29.01 \pm 4.30$ & $53.67 \pm 0.96^{\#}$ & $73.24 \pm 1.36^{* *}$ & $85.35 \pm 0.31^{* *}$ & $96.09 \pm 0.45^{\#}$ & $19.67 \pm 0.33$ & $38.50 \pm 1.33$ \\
\hline Vildagliptin & $26.27 \pm 2.82$ & $51.12 \pm 2.66^{* *}$ & $72.01 \pm 2.28^{*}$ & $85.06 \pm 1.27^{*}$ & $96.40 \pm 0.40^{\#}$ & $19.83 \pm 0.40$ & $34.33 \pm 0.88$ \\
\hline ANOVA P value & 0.2 & $0.0003^{\#}$ & $0.002^{* *}$ & $0.009^{* *}$ & $0.0001^{\#}$ & $0.0003^{\#}$ & $0.0009^{\#}$ \\
\hline
\end{tabular}

$\mathrm{p}^{*}<0.05 ;{ }^{* *}<0.01,{ }^{\#} \mathrm{p}<0.001$ as compared to control group. SEM: Standard error of the mean, ANOVA: Analysis of variance 
Table 2: Effect of various healing agents on resutured incision and dead space wounds. The Values are represented as mean \pm SEM (n=6)

\begin{tabular}{lll}
\hline Group (n=6) & Resutured incision Wound breaking strength (g) & Granulation tissue \\
\cline { 2 - 3 } & & Granuloma dry weight (mg \% of body weight) \\
\hline Control & $186.60 \pm 2.31$ & $32.33 \pm 1.20$ \\
Sitagliptin & $226.50 \pm 6.55$ & $45.35 \pm 0.42$ \\
Vildagliptin & $224.80 \pm 10.40$ & $42.33 \pm 1.35$ \\
ANOVA P value & $0.004^{* *}$ & $0.0001^{\#}$ \\
\hline
\end{tabular}

${ }^{* *} \mathrm{p}<0.01,{ }^{*} \mathrm{p}<0.001$ as compared to control group. SEM: Standard error of the mean, ANOVA: Analysis of variance

diabetic patients with ischemic foot ulcers are not amenable to surgical revascularization of lower limb arteries because of multiple distal stenoses. In addition, microangiopathy is a major contributor to the shortage of oxygen and nutrient supply to the granulation tissue, thus contributing to delay healing [13].

Animal wound healing models are important biological tools to understand basic processes of tissue repair and to develop and validate strategies for clinical treatment $[14,15]$. The results of the present study indicated that Sitagliptin and Vildagliptin enhanced wound healing of all the three types of wounds models.

The results of the present study could be attributed to their systemic absorption and promotion of angiogenesis at the wound site, as denoted by enhanced granulation tissue and increased collagen content in histological studies.

Drugs that augment the incretin system, i.e., GLP-1 agonists and DPP-4 inhibitors represent a novel class of antihyperglycemic agents that have shown to improve the health and survival of beta-cells, suppress glucagon, improve insulin resistance, and influence energy intake with minimal side effects [16].

Over time, these agents have shown to have a cardiac friendly profile, preserve neuronal cells and safeguard from neuronal degeneration, improve hepatic inflammation and hepatosteatosis, improve insulin resistance, promote weight loss, and induce satiety. There is growing evidence that they may also be renoprotective and help with wound healing [14].

Studies done on diabetic obese mice have shown that DPP-4 inhibition improves reepithelialization, reduces inflammation, and enhances the formation of myofibroblasts, all features of a healthier granulation tissue [17].

Few studies have shown that Vildagliptin may have the ability to improve wound healing by increasing angiogenesis in the wound environment, normalizing the rate of oxidative stress, and making positive changes to capillary density. It also increases the levels of hypoxia-inducible factor-1 and vascular endothelial growth factor, which has an important role in stimulating the growth of new capillaries in several organ systems and thus helps in stimulating neovascularization to accelerate healing of diabetic chronic ulcers [18].

\section{CONCLUSION}

Our findings demonstrate that Sitagliptin and Vildagliptin can improve healing, closure, and morphology of wounds in different wound models. These findings suggest that inhibition of DPP-4 enzymatic activity may support the impaired tissue regeneration process which needs to be confirmed clinically.

\section{CONFLICTS OF INTEREST}

All authors have none to declare.

\section{AUTHOR'S CONTRIBUTIONS}

Contribution of the $1^{\text {st }}$ author: Concept of design of study, acquisition, analysis, and interpretation of data. Drafting and revising the manuscript for important intellectual content.

Contribution of the $2^{\text {nd }}$ author: Acquisition of data and interpretation of the data. Author was involved in drafting the manuscript.

Contribution of the $3^{\text {rd }}$ author: Acquisition of data and interpretation of the data. Author was involved in drafting the manuscript.

\section{REFERENCES}

1. Brunton LL, Chabner BA, Knollmann BC. Goodman and Gilman's The Pharmacological Basis of Therapeutics. 12 ${ }^{\text {th }}$ ed. New York: McGraw Hill Publishers; 2011.

2. Longo DL, Fauci AS, Kasper DL, Hauser SL, Jameson JL, Loscalzo J. Harrison's Principles of Internal Medicine. $18^{\text {th }}$ ed. New York: McGraw Hill Publishers; 2012.

3. Pryce DT. A case of perforating ulcers of both feet associated with diabetes and ataxic symptoms. Lancet 1887;130:11-2.

4. Setacci C, de Donato G, Setacci F, Chisci E. Diabetic patients: Epidemiology and global impact. J Cardiovasc Surg (Torino) 2009;50:263-73

5. Robbins JM, Strauss G, Aron D, Long J, Kuba J, Kaplan Y. Mortality rates and diabetic foot ulcers: Is it time to communicate mortality risk to patients with diabetic foot ulceration? J Am Podiatr Med Assoc 2008;98:489-93.

6. Schürmann C, Linke A, Pilger K, Steinmetz C, Mark M, Pfeilschifter J, et al. The dipeptidyl peptidase-4 inhibitor linagliptin attenuates inflammation and accelerates epithelialisation in wounds of diabetic ob/ob mice. J Pharmacol Exp Ther 2012;342:71-80.

7. Ghosh MN. Fundamentals of Experimental Pharmacology. $4^{\text {th }}$ ed. Kolkata: Hilton And Company; 2005.

8. Rao KS, Patil PA, Malur PR. Promotion of cutaneous wound healing by famotidine in Wistar rats. Indian J Med Res 2007;125:149-54.

9. Turner RA. Screening Methods in Pharmacology. New York, London: Academic Press Inc; 1965.

10. Patil PA, Kulkarni DR. Effect of anti proliferative agents on healing of dead space wounds in rats. Ind J Med Res 1984;74:445-7.

11. D'Arcy PF, Howard EM, Muggleton PW, Townsend SB. The antiinflammatory action of griseofulvin in experimental animals. J Pharm Pharmacol 1960;12:659-65.

12. Dipasquale G, Meli A. Effect of body weight changes on the formation of cotton pellet induced granuloma. J Pharm Pharmacol 1965;17:379-82.

13. Yamaguchi Y, Yoshikawa K. Cutaneous wound healing: An update. J Dermatol 2001;28:521-34.

14. Mekala S, Kumar MN, Das L, Shetty N, Amuthan A, Vulli V, et al. Evaluation of wound healing activity of ethanolic extract of Lantana camara in streptozotocin induced diabetic rats. Int J Pharm Pharm Sci 2014;6:631-3

15. Bairy KL, Abhinav R, Satyam S. Evaluation of burn wound healing activity of topical regular insulin in non-diabetic and streptozocininduced diabetic rats. Int J Pharm Pharm Sci 2014;6:127-30.

16. Gupta V. Pleiotropic effects of incretins. Indian J Endocrinol Metab 2012;16:S47-56.

17. Avogaro A, Fadini GP. The effects of dipeptidyl peptidase-4 inhibition on microvascular diabetes complications. Diabetes Care 2014;37:2884-94.

18. Marfella R, Sasso FC, Rizzo MR, Paolisso P, Barbieri M, Padovano V, et al. Dipeptidyl peptidase 4 inhibition may facilitate healing of chronic foot ulcers in patients with type 2 diabetes. Exp Diabetes Res 2012;2012:892706. 